\title{
Study of $\boldsymbol{H}$. Pylori Infection in Patients with Portal Hypertensive Gastropathy
}

\author{
Hosam Ibrahim $^{1}$, Nancy Y Asaad ${ }^{2}$, Hosam Eldin M. Seleem ${ }^{1}$ \\ and Israa MA Nouh ${ }^{1}$ \\ Tropical Medicine ${ }^{1}$ and pathology ${ }^{2}$ Departments, Faculty of Medicine, \\ Menoufia University, Egypt
}

Corresponding Author Israa MA Nouh

Mobile:

$+201222145552$

E mail: alaa_nouh@hotmail. com

Key words: Portal hypertensive Gastropathy; H pylori
Background and study aim: The association between $H$. pylori infection and cirrhosis in patients with hepatitis $\mathrm{C}$ virus has been documented in different parts of the world. Eradication treatment may prove beneficial in those patients with chronic hepatitis $\mathrm{C}$. The aim of the present study was to study $H$. pylori infection in patients with portal hypertensive gastropathy.

Patients and Methods: This study was conducted on 60 patients; 45 patients with portal hypertensive gastropathy (Group A). In addition to 15 patients with chronic gastritis without portal hypertension (Group B). All patients were subjected to full history tacking and complete physical examination. Routine laboratory investigation including, CBC, PT, PC, INR, SGOT, SGPT, S. Albumin, S. Bilirubin. Radiological examination including abdominal ultrasound, and Doppler study for Portal vein. Upper GIT endoscopy, and biopsies from the antrum. Histopathological examination of the biopsies for assessment of congestive

\section{INTRODUCTION}

PHG while extremely common in patients with portal hypertension, is an uncommon cause of significant bleeding in these patients. When portal hypertensive gastropathy is the sole cause of bleeding, there is diffuse mucosal oozing with no other lesions, such as varices, to account for the GI bleeding and anemia. The mucosa is friable, and bleeding presumably occurs when the ectatic vessels rupture. The severity of gastropathy is related to the level of portal pressure, the level of hepatic vascular resistance, and the degree of reduction in hepatic blood flow [1]. gastropathy and $H$. pylori infestation if present.

Results: This study demonstrated that the $60 \%$ of patients of group A and $66 \%$ of patients of group B have $H$. pylori infection. There was no predilection for $H$. pylori infections in patients with PHG than those in patients with gastritis. In group A, 53\% of patients with varices had $H$. pylori infection while $47 \%$ did not have $H$. pylori infection. Also, $76 \%$ of the non $H$. pylori patients had esophageal varices while $24 \%$ of patients with non $H$. pylori subgroup had no varices. Additionally, patients of group A with mild PHG and $H$ pylori constituted $26.5 \%$, those with moderate PHG and $H$ pylori constituted $47 \%$ while patients with severe PHG and H pylori constituted $26.5 \%$.

Conclusion: This study demonstrated that there is no predilection concerning the presence of $H$ pylori infection in patients with PHG and there is no relation between the degree of PHG and the presence of $H$ pylori infection.

PHG may correlate with the severity of liver disease. Gastric mucosal blood flow is increased in patients with cirrhosis and PHG compared with those without gastropathy, suggesting that the pathogenesis of this disorder may be related to both congestion and hyperemia in the stomach [2].

H. pylori is recognized as a pathogen of upper gastrointestinal diseases, such as acute and chronic gastritis, duodenal and gastric ulcers and mucosa-associated lymphoid tissue (MALT) lymphoma. H. pylori has also been closely associated with development of gastric adenocarcinoma. 
$H$. pylori has been reported to induce hepatotoxicity in vitro. Furthermore, several investigators have reported a high prevalence of $H$. pylori infection in patients with chronic liver diseases [3]. Although H. pylori is generally believed to be sensitive to bile, several studies have shown that $H$. pylori is detectable in the liver and biliary tract and that $H$. pylori can survive in bile-rich environment. These findings indicate that bile- resistant $H$. pylori may survive in the liver and biliary tract. The association between $H$. pylori infection and cirrhosis in patients with hepatitis $\mathrm{C}$ virus has been documented in different parts of the world. Remarkable increase in the $H$. pylori prevalence with advancing hepatic lesions, has been demonstrated in Egypt. Moreover, eradication treatment may prove beneficial in those patients with chronic hepatitis $C$ [4].

\section{Aim of the work}

The aim of the present work was to study $H$. pylori infection in patients with portal hypertensive gastropathy.

\section{PATIENTS AND METHODS}

This study has been conducted on 60 patients attending endoscopy unit of National Hepatology Institute and Tropical Medicine Department classified into two groups :Group (A)includes 45 patients with portal hypertensive gastropathy (PHG), they were 32 males and 13 females, their ages ranged from 19 to 63 years and group (B) included 15 patients with chronic gastritis without portal hypertension, they were 10 males and 5 females, their ages ranged from 24 to 55 years. All patients were subjected to full history tacking and complete physical examination, laboratory investigation (CBC, INR, SGOT, SGPT, S. albumin, S. bilirubin), abdominal ultrasound with Doppler study, upper GIT endoscopy, and biopsies from gastric antrum and body for histopathological examination and detection of $H$. pylori infection. PHG were classified endoscopically into three grades based on Tanoue et al classification: G I (mild mucosal reddening), G II (severe redness and a fine reticular pattern separating the areas of raised edematous mucosa "mosaic"), G III (hemorrhagic spots plus G II). Histopathological features of PHG include dilatation of the capillaries \& collecting venules in submucosa and in severe cases these vessels become markedly dilated and extend to mucosa which become severely congested and edematous.

\section{RESULTS}

The results of the present study showed that there were no statistical significant differences between the two groups concerning gender distribution and age. The clinical examination showed that patients of group A demonstrate that $11 \%$ had pallor, $20 \%$ had tinge of jaundice, $17 \%$ showed lower limb edema, $71 \%$ had hepatomegaly and $40 \%$ had splenomegaly. Patients of group B were clinically free according to the inclusion criteria. As regard liver functions, there was a statistically significant deterioration of some liver function tests in patients of group A than those of group B. Coming to $\mathrm{CBC}$, there were statistically significant decrease in RBCs, hemoglobin, and platelets count, while no significant differences in WBCs and eosinophils.

Table (1) shows that there was statistically significant difference between the two groups regarding haemoglobin and platelets. There was no statistically significant difference between the two groups regarding WBCs and eosinophils (Fig. 1).

Concerning abdominal ultrasound, the results showed that patients of group A, $45 \%$ of them showed chronic liver disease while $55 \%$ showed manifestation of cirrhosis. Also $71 \%$ had splenomegaly, More than $95 \%$ had dilated PV and more than $33 \%$ showed collateral vessels of portosystemic circulation.

Table (2) shows that the direction of blood flow is hepatopedal in all patients of gastritis while in patients with PHG only 58\% was hepatopedal while $31 \%$ was hepatofugal and $11 \%$ was bidirectional. It also shows that although the flow was faster in gastritis group than the PGH group, yet there was no statistical significant difference as regards the PV velocity among the studied groups.

Coming to the endoscopic findings, this study demonstrated that among patients in group A, $31 \%$ had esophageal varices, $44 \%$ had mild PHG, 36\% showed moderate and 20\% had severe PHG. While patients of group B showed no manifestation of $\mathrm{PHG}$, but peptic erosions; mild and moderate in some of them (Figs.2).

Table (3) shows that there was statistically significant difference between the two groups 
regarding the presence of esophageal varices and PHG and no statistically significant difference between the two groups regarding inflammation.

Table (4) represents the distribution of $H$. pylori in histopathological study of gastric biopsy specimen among studied groups. There was no significant difference between studied groups as regard presence of $H$. pylori infection. $66.67 \%$ of PHG group had $H$. pylori infection versus $60 \%$ of gastritis group meaning that there is no specific predilection for $H$. pylori infections in patients with PHG than those in patients with gastritis.
Moreover, there was no significant difference between severity of PHG and the presence of $H$. pylori infection (table 5)

Table (6) shows that there was statistically significant difference between the two groups regarding pathological finding concerning the presence of lymphoid aggregates and the presence of mucosal cell atrophy which show a highly significant increase in PHG group. There was no statistical significant difference regarding the immunological activity and the presence of metaplasia or dysplasia.

Table (1): Main elements of the blood picture of the studied groups

\begin{tabular}{|c|c|c||c|c|}
\hline \multirow{2}{*}{ Parameter } & \multicolumn{2}{|c|}{ Groups } & \multirow{2}{*|}{ T test } & P value \\
\cline { 2 - 5 } & PHG (45) & Gastritis (15) & \\
\hline Haemoglobin & $10.98 \pm 1.61$ & $13.02 \pm 1.32$ & 4.27 & $<0.001$ \\
\hline Platelts & $98.33 \pm 46.04$ & $285.26 \pm 74.28$ & 10.68 & $<0.001$ \\
\hline WBCs & $6.14 \pm 4.46$ & $4.43 \pm 2.07$ & 0.98 & $>0.05$ \\
\hline Eosinophils & $0.3 \%$ & $0.5 \%$ & 0.89 & $>0.05$ \\
\hline
\end{tabular}

\section{Child distibution in PHG Group}

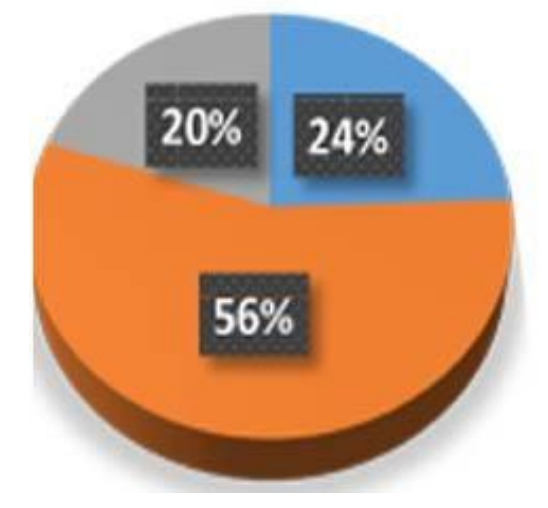

anild $\mathrm{A}$

anild $\mathrm{B}$

achild C

Figure (1) :Child classification of the studied group 
Table (2): Direction of Blood flow through the PV of the studied groups

\begin{tabular}{|c|c|c|c||c||}
\hline \multirow{2}{*}{ Parameter } & \multicolumn{2}{|c|}{ Groups } & \multirow{2}{*||}{ Chi square } & P value \\
\cline { 2 - 5 } & $\begin{array}{c}\text { PHG } \\
(45)\end{array}$ & $\begin{array}{c}\text { Gastritis } \\
(15)\end{array}$ & & \\
\hline Flow & $26(58 \%)$ & 15 & & \\
Hepatopedal & $14(31 \%)$ & 0 & 25.4 & $<0.05$ \\
Hepatofugal & $5(11 \%)$ & 0 & & \\
Bi-directional & & & & $>0.05$ \\
\hline Velocity & $5.4 \pm 13.1$ & $13.6 \pm 4.0$ & 0.01 & $>0.05$ \\
cm/sec. & St. Dev. & 5.4 & &
\end{tabular}
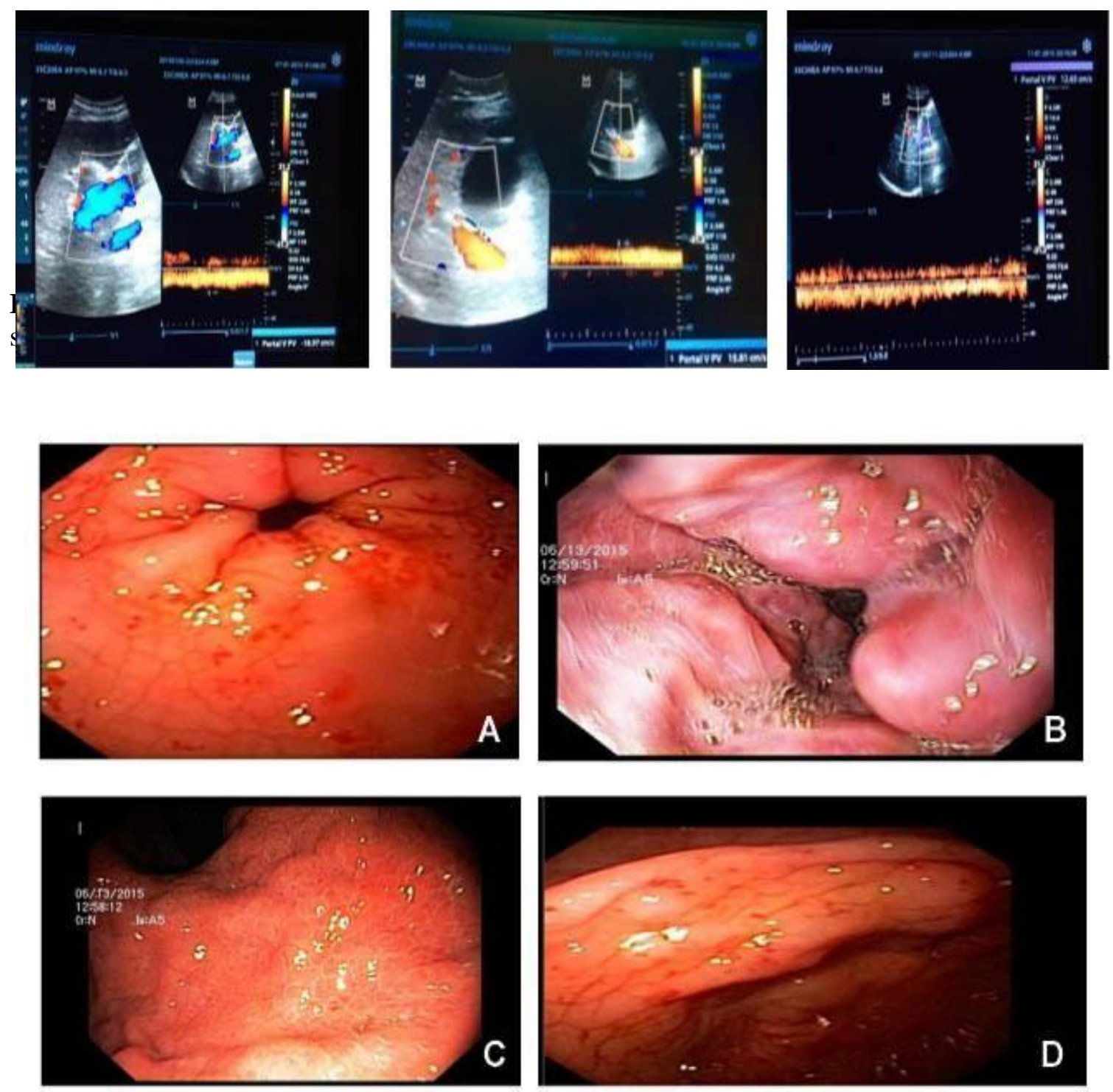

Figure (2): Endoscopic findings where (a) Mild GAVE, (b) esophageal varices, (c) Mozaic mucosa and (d) Incisural congestion 
Table (3): Endoscopic finding of the studied groups

\begin{tabular}{|l|c|c|c|c|}
\hline \multirow{2}{*}{ Parameter } & \multicolumn{2}{|c|}{ Groups } & \multirow{2}{*}{ Chi square } & \multirow{2}{*}{ P-value } \\
\cline { 2 - 3 } & PHG (45) & Gastritis (15) & & \\
\hline Varices & & & & \\
Present & $31(68.89 \%)$ & $0(0 \%)$ & & \\
Absent & $14(31.11 \%)$ & $15(100 \%)$ & & \\
\hline PHG & $0(0 \%)$ & $15(100 \%)$ & & \\
No & $18(40 \%)$ & & 20.03 & \\
Mild & $17(37.78 \%)$ & & & \\
Moderate & $10(22.22 \%)$ & & & \\
Sever & $17(37.78 \%)$ & $11(73.33 \%)$ & 5.89 & \\
\hline Inflammation & $26(57.78 \%)$ & $4(26.67 \%)$ & & \\
Mild & $2(4.44 \%)$ & $0(0 \%)$ & & \\
Moderate & & & & \\
Sever & & & & \\
\hline
\end{tabular}

Table (4) : H. pylori infection detected in histopathological study of gastric biopsy specimen

\begin{tabular}{|l|c|c|c|c|}
\hline \multirow{2}{*}{ Parameter } & \multicolumn{2}{|c|}{ Groups } & \multirow{2}{*}{ Chi square } & \multirow{2}{*}{ P-value } \\
\cline { 2 - 3 } & $\begin{array}{c}\text { PHG } \\
\text { (45 patients) } \\
\text { No. }(\%)\end{array}$ & $\begin{array}{c}\text { Gastritis } \\
(\mathbf{1 5} \text { patients })\end{array}$ & \multirow{2}{*}{0.22} & $>0.05$ \\
\hline H. pylori & $30(66.67 \%)$ & $9(60 \%)$ & $6(40 \%)$ & \\
Positive & $15(33.33 \%)$ & Negative &
\end{tabular}

Table (5): Distribution $H$ pylori infection in different grades of PHG in group A patients

\begin{tabular}{|c|c|c|c|c|}
\hline \multirow[b]{2}{*}{ Parameter } & \multicolumn{2}{|c|}{ PHG(45 patients) } & \multirow[b]{2}{*}{ Chi square } & \multirow[b]{2}{*}{ P-value } \\
\hline & $\begin{array}{c}\text { Non } H . \text { pylori } \\
\text { (15 patients) } \\
(33.33 \%) \\
\end{array}$ & $\begin{array}{c}\text { H. pylori } \\
\text { (30 patients) } \\
(66.67 \%)\end{array}$ & & \\
\hline $\begin{array}{l}\text { PHG } \\
\text { Mild } \\
\text { Moderate } \\
\text { Sever }\end{array}$ & $\begin{array}{l}4(26.67 \%) \\
7(46.67 \%) \\
4(26.67 \%)\end{array}$ & $\begin{array}{l}14(46.67 \%) \\
10(33.33 \%) \\
6(20 \%)\end{array}$ & 5.03 & $>0.05$ \\
\hline
\end{tabular}


Table (6): Histopathological findings of the studied groups

\begin{tabular}{|c|c|c|c|c|c|c|}
\hline \multirow{3}{*}{ Pathology } & \multicolumn{4}{|c|}{ Groups } & \multirow{3}{*}{$\begin{array}{l}\text { Chi } \\
\text { square }\end{array}$} & \multirow{3}{*}{ P -value } \\
\hline & \multicolumn{2}{|c|}{ PHG(45) } & \multicolumn{2}{|c|}{ Gastritis (15) } & & \\
\hline & No. & $\%$ & No. & $\%$ & & \\
\hline $\begin{array}{l}\text { Lymphoid follicles } \\
\text { Aggregates } \\
\text { Negative }\end{array}$ & $\begin{array}{l}22 \\
23\end{array}$ & $\begin{array}{l}48 \% \\
52 \%\end{array}$ & $\begin{array}{c}1 \\
14\end{array}$ & $\begin{array}{c}6 \% \\
94 \%\end{array}$ & 13.59 & $<0.01$ \\
\hline $\begin{array}{l}\text { Inflammatory activity } \\
\text { Absent } \\
\text { Present }\end{array}$ & $\begin{array}{l}24 \\
21\end{array}$ & $\begin{array}{l}44.44 \% \\
46.66 \%\end{array}$ & $\begin{array}{l}6 \\
9\end{array}$ & $\begin{array}{l}40 \% \\
60 \%\end{array}$ & 2.98 & $>0.05$ \\
\hline $\begin{array}{l}\text { Mucosal atrophy } \\
\text { Present } \\
\text { Absent }\end{array}$ & $\begin{array}{l}13 \\
32\end{array}$ & $\begin{array}{l}28.89 \% \\
71.11 \%\end{array}$ & $\begin{array}{c}0 \\
15\end{array}$ & $\begin{array}{c}0 \% \\
100 \%\end{array}$ & 27.59 & $>0.05$ \\
\hline Metaplasia & 0 & $0 \%$ & 0 & $0 \%$ & 1 & $>0.05$ \\
\hline Dysplasia & 0 & $0 \%$ & 0 & $0 \%$ & 1 & $>0.05$ \\
\hline $\begin{array}{l}\text { Presence of } H . \text { pylori } \\
\text { infection }\end{array}$ & 30 & $66.67 \%$ & 9 & $60 \%$ & 0.22 & $>0.05$ \\
\hline
\end{tabular}

Features of PHG were present in all PHG group patients while it was absent in all gastritis group patients.

\section{DISCUSSION}

In the past few years, several studies have observed that $H$. pylori was associated with the pathogenesis of human enterohepatic diseases [6].

The study shows that there was no statistically significant difference between the two groups regarding $H$ pylori. Although $H$. pylori infection was higher $(66.6 \%)$ in PHG group than in gastritis group (60\%), yet there was no statistical difference. That goes with many authors who reported that whether Helicobacter species could act as a cofactor in the progression towards cirrhosis and carcinogenesis in humans with viral hepatitis is still under review [5].

Several investigators have evaluated the effect of $H$. pylori on liver cirrhosis, PHG and encephalopathy with controversial results. Some reports have shown a higher seroprevalence and suggested a synergistic effect of $H$. pylori on liver cirrhosis and PHG. However, this increased prevalence is associated with a negative histology and is not influenced by the cause of cirrhosis, PHG, Child class or gender. Most studies have not found any correlation between $H$. pylori and PHG. In contrast, other studies have reported a markedly lower prevalence of $H$. pylori in cirrhotics with duodenal ulcer compared to controls [14]
In a study by Sathar et al.; the main results were that: a) the prevalence of infection was higher in cases (cirrhotics with PHG) than controls (cirrhotics without PHG) $(44.3 \%$ vs. $27.1 \%$, $\mathrm{P}=0.034$; OR 2.134, 95\% CI 1.052-4.327), and b) the prevalence of severe PHG was higher in the $31 \mathrm{H}$. pylori infected compared to the 39 uninfected patients (61.3\%vs. $12.8 \%, \mathrm{P}<0.001$; OR 10.767, 95\% CI 3.293-35.205). Since the pathogenesis of PHG is not completely disclosed and the role of $H$. pylori in such a field is still controversial - any new information is welcomed. Secondly, this study found that a significantly higher $H$. pylori seroprevalence rate in cirrhotics with severe PHG (19/24, 79.2\%) compared to those with mild PHG $(12 / 46,26.1 \%)$. Consequently, it was concluded that $H$. Pylori infection is not only associated with PHG in cirrhotics, but also with more severe PHG [12].

This was also in agreement with Batmanabane et al., who reported that not only a significant association of $H$. pylori with PHG in cirrhosis but also with the severity of PHG. The authors suggested that gastric mucosa in cirrhotics may provide a hospitable environment for $H$. pylori colonization especially when there is severe hemorrhagic congestion and edema of the mucosa [16]. 
In another study by Zhu; $H$. pylori infection was confirmed in 19 of $34(55.9 \%)$ patients and in 74 of $136(54.4 \%)$ controls. There was no significant difference in $H$. pylori infection rates of the patients and controls $(\mathrm{P}<0.05)$. The findings showed that the presence of $H$. pylori was not closely associated with portal hypertensive gastropathy. In addition, there was no significant difference in $H$. pylori infection rates in patients sub-grouped by severity of gastropathy, duration of the disease and Child-Pugh classification of liver function $(\mathrm{P}<0.05)$. The results suggested that factors other than H. pylori infection may be important in the pathogenesis of endoscopic changes. The study also concluded that: prevalence of $H$. pylori infection was not higher in PHG patients than in controls with chronic superficial gastritis who were matched by sex and age. $H$. pylori infection is unrelated to the severity of endoscopic changes, duration of the disease and Child-Pugh classification of liver function. $H$. pylori infection is not the only essential factor for the development of PHG [13].

Both PHG and H. pylori without PHG significantly increase inducible nitric oxide synthase (iNOS) production. In fact, there is a positive correlation between the expression of iNOS and the severity of PHG. However there has been no evidence of synergistic action between $H$. pylori and PHG on iNOS expression [15]

Other studies reported the prevalence of Helicobacter infection in patients with $\mathrm{HCV}$ related chronic hepatitis, cirrhosis and HCC [4]. The discovery of the presence of Helicobacter species DNA in liver material from patients with liver disease has led to the challenging hypothesis that these bacteria may play a role in the evolution of hepatic diseases from chronic viral hepatitis to cirrhosis and HCC. Determinants of this evolution are not yet fully understood, including those occurring in HCV-positive patients [7]. As Helicobacter hepaticus has been shown to cause both chronic hepatitis and HCC in mice, it is suggested that differences in the progression of chronic hepatitis $\mathrm{C}$ may be due to a cofactor stemming from co-infection by bacteria especially H. Pylori and other Helicobacter species [8]. Several aspects of the relation between Helicobacter species (particularly $H$. pylori) and liver diseases have been assessed in human beings [9]. The higher prevalence of Helicobacter species associated with more advanced stages of liver disease supports the possibility of their role in the progression of chronic hepatitis towards cirrhosis and HCC [3]. Determinants of this evolution are not yet fully understood, including those occurring in HCVpositive patients [5]. Several studies have evidenced a high sero- prevalence of $H$. pylori among cirrhotic patients, and this may explain the frequent occurrence of peptic ulcer disease in these patients [11].

However, H. pylori prevalence in other studies was found to range widely from $23 \%$ to $79 \%$ and from $22 \%$ to $81 \%$ in cirrhotics with mild and severe PHG [11].

\section{CONCLUSION}

On the light of this study, there is no statistical significant specific predilection concerning the presence of $H$ pylori infection in patients with portal hypertensive gastropathy. There is no relation between the degree of portal hypertension and the presence of $H$ pylori infection.

Funding: None.

Conflicts of interest: None.

Ethical approval: Approved.

\section{REFERENCES}

1- Primignani M, Carpinelli L, Preatoni P, Battaglia G, Carta A, Prada A et al. Natural history of portal hypertensive gastropathy in patients with liver cirrhosis. The New Italian Endoscopic Club for the study and treatment of esophageal varices (NIEC). Gastroenterology, 2000;119(1):181

2- Fontana RJ, Sanyal AJ, Mehta S, Doherty MC, Neuschwander-Tetri BA, Everson GT et al. Portal hypertensive gastropathy in chronic hepatitis $\mathrm{C}$ patients with bridging fibrosis and compensated cirrhosis: results from the HALT-C trial. Am $J$ Gastroenterol, 2006; 101(5):983.

3- Pellicano R, Me'nard A, Rizzetto M, Me'graud F. Helicobacter species liver diseases: association or causation?. The Lancet Infect Dis, 2008; 8(4): 254-260.

4- El-Masry S, El-Shahat M, Badra G, Aboel-Nour M, Lotfy M. Helicobacter pylori and hepatitis C virus coinfection in Egyptian patients. J Glob Infect Dis, 2010; 2(1):4.

5- Fagoonee S, PellicanoR, Rizzetto M, Ponzetto A. The journey from hepatitis to hepato-cellular carcinoma. Bridging role of Helicobacter species. Panminerva Med, 2001; 43(4):279.

6- Solnick J, Schauer D. Emergence of diverse Helicobacter species in the pathogenesis of gastric and enterohepatic diseases. Clin Microbiol Rev, 2001; 14(1):59. 
7- Rocha M, Avenaud P, Menard A, Le Bail B, Balabaud C, Bioulac-Sage P et al. Association of Helicobacter species with hepatitis C cirrhosis with or without hepatocellular carcinoma. Gut 2005; 54(3):396.

8- Ponzetto A, PellicanoR, Leone N, Cutufia MA, Turrini F, Grigioni WF et al. Helicobacter infection and cirrhosis in hepatitis $\mathrm{C}$ virus carriage: is it an innocent bystander or a troublemaker?. Med Hypotheses, 2000; 54(2):

9- Dikshit RP, Mathur G, Mhatre S, Yeole BB. Epidemiological review of gastric cancer in India. Indian J Med Paediatr Oncol, 2011; 32(1)3-11.

10- Tiwari S, Khan A, Ibrahim M, Habeeb M, Habibullah C. Helicobacter pylori and other Helicobacter species DNA in human bile samples from patients with various hepatobiliary diseases. World J Gastroenterol, 2006; 12(14):2181.

11- ZulloA, Hassan C, Morini S. Helicobacter pylori infection in patients with liver cirrhosis: facts and fictions. Dig Liver Dis 2003; 35(3):197-205.

12- Sathar SA, Kunnathuparambil SG, Sreesh S, Narayanan P, Vinayakumar KR. (2014): Helicobacter pyloriinfection in patients with liver cirrhosis: prevalence and association with portal hypertensive gastropathy. Ann Gastroenterol; 27:48-52.
13- Zhu HH. Prevalence of Helicobacter pylori in cirrhotic patients with portal hypertensive gastropathy. World J Gastroenterol, 1996; 2(2): 104-105

14- Al Mofleh. Does Helicobacter pylori Affect Portal Hypertensive Gastropathy? The Saudi Journal of Gastroenterology, 2007; Volume 13, Number 2

15- Arafa UA, Fujiwara Y, Higuchi K, Shiba M, Uchida T, Watanabe T, et al. No additive effect between Helicobacter pylori infection and portal Expression of hypertensive gastropathy on inducible nitric oxide synthase expression in gastric mucosa of cirrhotic patients. Dig Dis Sci; 2003; 48:162-8.

16- Batmanabane V, Kate V, Ananthakrishnan N. Prevalence of Helicobacter pylori in patients with portal hypertensive gastropathy - a study from South India. Med Sci Monit 2004; 10:133-136.

17- Tanoue K, Hashizume M, Wada H, Ohta M, Kitano S, Sugimachi K. Effects of endoscopic injection sclerotherapy on portal hypertensive gastropathy: a prospective study. Gastrointest Endosc 1992; 38:582-585.

Peer reviewer: Tarik Zaher, Professor of Tropical Medicine and Hepatogastroenterology, Faculty of Medicine, Zagazig University, Egypt. Editor: Mohamad Emara, Lecturer of Tropical Medicine and Hepatogastroenterology, Faculty of Medicine, Zagazig University, Egypt 